\title{
Simulation of electrical properties of InP/InGaAs heterojunction bipolar transistors in microwave
}

\author{
Yamina BERRICHI ${ }^{* 1}$, Kheireddine GHAFFOUR ${ }^{2}$ \\ ${ }^{1}$ Physics Department, Faculty of Sciences, University of Abou-bekr Belkaid, Algeria \\ ${ }^{2}$ Electronics department, Faculty of Technology, University of Abou-bekr Belkaid, Algeria \\ *Corresponding author: E-mail: amina2010271@yahoo.fr
}

Keywords: Transistor, HBT, InP/InGaAs, NPN, Heterojunction, Microwave

\begin{abstract}
This work is devoted to the simulation of electrical characteristics of the $\mathrm{InP} / \mathrm{InGaAs}$ double heterojunction bipolar transistor (DHBT) NPN type, the essential aim for extracting the maximum and transition frequencies are important indicators for the use of the component in the microwave. InP/InGaAs DHBTs with surface of $0.25 \times 0.73 \mu \mathrm{m}^{2}$, the simulation of this structure has demonstrated a maximum current gain cutoff frequency $\mathrm{f}_{\mathrm{T}}$ of $900 \mathrm{GHz}$, with a simultaneous maximum power gain cutoff frequency $\mathrm{f}_{\mathrm{MAX}}$ of $500 \mathrm{GHz}$ at the current density $\mathrm{J}_{\mathrm{c}}$ of $66 \mathrm{~m} \mathrm{~A} / \mu \mathrm{m}$. tapical $\mathrm{BV}_{\mathrm{CE}}$ values exceed $1.9 \mathrm{~V}$.
\end{abstract}

\section{Introduction}

The InP/InGaAs NPN double heterojontion bipolar transistor is very good candidates for many applications because of their advantage: Lower surface recombination, super electron, lower turn-on voltage, higher electron mobility, better thermal dissipation, better microwave performance.

The InP/InGaAs double heterojuntion bipolar transistor (DHBT), is the subject of this work, it is emerging as a very promising high speed device for a wide variety of applications, Discrete $\mathrm{InP} / \mathrm{InGaAs} \mathrm{HBTs}$ capable of operating well above 765 at $25^{\circ} \mathrm{c}$ and $845 \mathrm{GHz}$ at $-55^{\circ} \mathrm{C}$ have been demonstrated experimentally [1].

In this paper we have presented electronic characteristic of $\mathrm{InP} / \mathrm{InGaAs}$ HBTs over a wide range of frequencies simulated.

Many parameters will be specifying for the simulation, once the mesh, geometry, doping profiles, method and physical models.

\section{Model of simulation}

The modeling of the transport of charge carriers in semiconductor structures is more or less complex according to the degree of approximation to be taken to account properly experimentally observed properties. If quantum effects are taken into account, transport can then be modeled with a classic approach: Fermi-Dirac statistics. And for solving equations semiconductors systems, we chose the method of Newton.

\section{Resultats and discusion}

Structure of simulation

The layer structure of the InP/InGaAs DHBT is shown in fig 1 . 


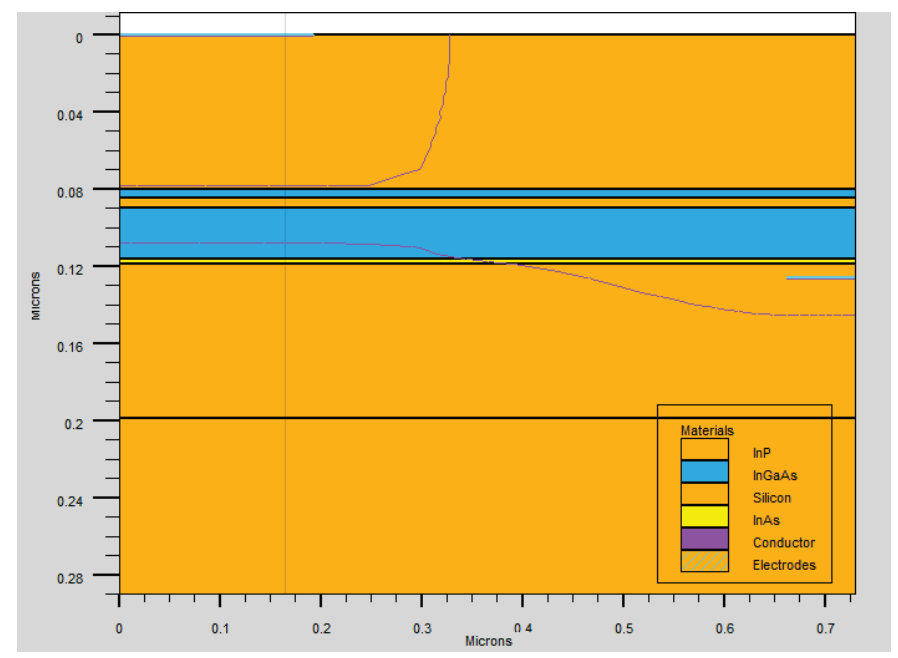

Fig. 1. Structure of InP / InGaAs DHBT.

As shown in table I, the HBT consists of $80 \mathrm{~nm}$ thick emitter, $30 \mathrm{~nm}$ thick base, $26 \mathrm{~nm}$ thick collector and $80 \mathrm{~nm}$ thick substrate.

\section{TABLE I: PARAMETERS DEFINITION OF MESH AND DOPING}

\begin{tabular}{|c|c|c|c|}
\hline Electrodes & $\begin{array}{l}\text { Dopage } \\
\left(\mathrm{cm}^{-3}\right)\end{array}$ & $\begin{array}{l}\text { Peak and junction } \\
\text { doping }\end{array}$ & $\begin{array}{l}\text { Thickness } \\
(\mathrm{nm})\end{array}$ \\
\hline $\begin{array}{l}\text { surface } \\
\text { concentration }\end{array}$ & $1 \times 10^{15}$ & & I \\
\hline Emitter (InP) & $7 \times 10^{19}$ & junc $=0.078$ & 80 \\
\hline layer (InGaAs) & $\begin{array}{l}\text { Non } \\
\text { dopé }\end{array}$ & & 5 \\
\hline Layer (AsGa) & $\begin{array}{l}\text { Non } \\
\text { dopé }\end{array}$ & & 5 \\
\hline Base (InGaAs) & $\begin{array}{l}3 \times 10^{19} \\
5 \times 10^{19}\end{array}$ & $\begin{array}{l}\text { junc }=0.11 \\
\text { peak }=0.09 \\
\text { char }=0.05\end{array}$ & 26 \\
\hline Layer (InAs) & $\begin{array}{l}\text { Non } \\
\text { dopé }\end{array}$ & & 3 \\
\hline Collector (InP) & $3 \times 10^{19}$ & peak $=0.19$ & 80 \\
\hline Substrat (InP) & 1 & 1 & 10 \\
\hline
\end{tabular}

The Figure 2 shown the collector and base current of InP/InGaAs DHBT, biased in the forward active mode of operation with $\mathrm{V}_{\mathrm{C}}=0.7 \mathrm{~V}$. 


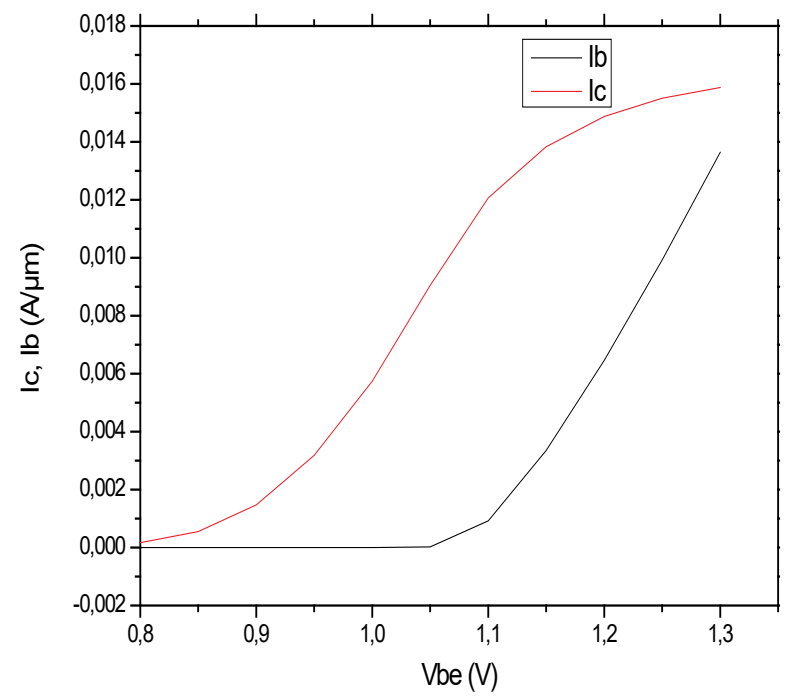

Fig. 2. Gummel plot of InP / InGaAs DHBT

A low polarization $\left(0 \mathrm{~V}<\mathrm{V}_{\mathrm{BE}}<1.05\right.$, we can observe the current components of the base $\left(\mathrm{I}_{\mathrm{B}}<\right.$ 1nA) called "non-ideal".

For intermediate polarizations $\left(1.05 \mathrm{~V}<\mathrm{V}_{\mathrm{BE}}<1.3\right)$ the base current and the collector current have ideal behavior.

With high polarization $\left(\mathrm{V}_{\mathrm{BE}}>1.3\right)$, collector current is reduced. Several reasons explain this: the influence of the base resistors and the quasi-saturation phenomenon.

Frequency analysis

The Figure 3 shows the dynamic and unilateral gain of InP / InGaAs DHBT.

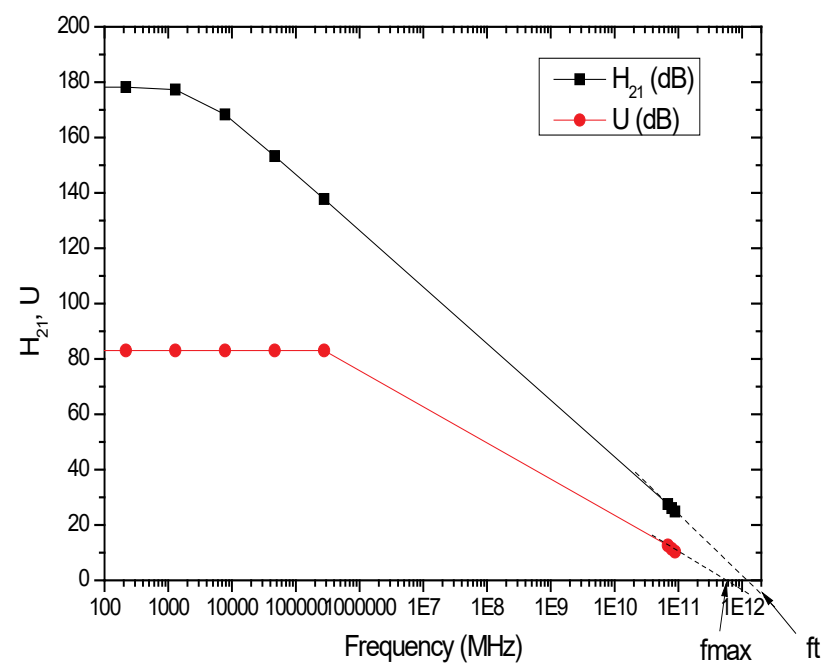

Fig.3. Dynamic and unilateral gain of InP / InGaAs DHBT.

The value of $\mathrm{f}_{\mathrm{T}}$ as found by extrapolation (at $-20 \mathrm{~dB} / \mathrm{decade}$ ) of dynamic gain to $0 \mathrm{~dB}$ [2], this extrapolated value shall be denoted by $\mathrm{H}_{21}$, the value of $\mathrm{f}_{\mathrm{MAX}}$ as found by extrapolation (at $-20 \mathrm{~dB} /$ decade) of unilateral gain to $0 \mathrm{~dB}$ [2], this extrapolated value shall be denoted by $\mathrm{U}$. 
TABLE II COMPARISON BETWEEN OUR RESULTATS AND OTHER WORK

\begin{tabular}{|l|l|l|l|}
\hline & $\mathrm{ft}(\mathrm{GHz})$ & $\begin{array}{l}\text { fmax } \\
(\mathrm{GHz})\end{array}$ & ref \\
\hline $\begin{array}{l}\text { InP/InGaAs } \\
\text { HBT }\end{array}$ & 765 & 227 & {$[3]$} \\
& $\begin{array}{l}(294 \mathrm{~K}) \\
(245 \\
(218 \mathrm{~K})\end{array}$ & $\begin{array}{l}263 \\
(218 \mathrm{~K})\end{array}$ & \\
& 360 & $800 \mathrm{~K}$ & {$[4]$} \\
\hline $\begin{array}{l}\text { InP/InGaAs } \\
\text { HBT }\end{array}$ & $(294 \mathrm{~K})$ & & \\
\hline $\begin{array}{l}\text { InP/InGaAs } \\
\text { HBT }\end{array}$ & 900 & 500 & Our resultants \\
\hline
\end{tabular}

The HBTs were characterized network analyzer from $100 \mathrm{MHz}$ to $89 \mathrm{GHz}$. The current gain and unilateral gain for a $0.25 \times 0.73 \mu \mathrm{m}^{2} \mathrm{HBT}$ are shown in Fig.3, successively.

A summary of the characteristic of the most recent high-speed bipolar transistor is shown in table II. The $f_{T}$ and $f_{\max }$ product for the InP/InGaAs DHTs devices exceeds $900 \mathrm{GHz}$ and $500 \mathrm{GHz}$ successively, in comparison by the experimentally results of the [3], [4], the values obtained of the maximum current gain cutoff frequency $f_{t}$ and maximum power gain cutoff frequency $f_{M A X}$ is compared with the experimental results.

On the other hand, we find maximum power gain cutoff frequency $f_{\mathrm{MAX}}$ smaller than the maximum current gain cutoff frequency $f_{t}$ frequency that becomes the high resistivity of the base region $\left(\mathrm{R}_{\mathrm{B}}\right)$.

\section{Conclusion}

This paper presents an extraction of the maximum current gain cutoff frequency $\left(f_{T}\right.$ is $\left.900 \mathrm{GHz}\right)$ and maximum power gain cutoff frequency $\mathrm{f}_{\mathrm{MAX}}\left(\mathrm{f}_{\mathrm{MAX}}\right.$ is $500 \mathrm{GHz}$ ) parameters in the microwave. Our resultats prove the quality of the model and the method. Future work will pursue reduction in access resistivity of the base to improve device performance.

\section{References}

[1] Snodgrass W, Hafez W, Harff N, Feng M. Pseudomorphic heterojunction bipolar transistor (PHBTs) experimentally demonstrating $\mathrm{ft}=765 \mathrm{GHz}$ at $25^{\circ} \mathrm{C}$ increasing to $\mathrm{ft}=845 \mathrm{GHz}$ at $-55^{\circ} \mathrm{C}$. Présenté au IEDM (IEEE), 2006.

[2] S. Lee, H.J.Karim, M.Urteaga, S. Krishnan, Y. Wei, M. Dahlstrom and M. Rodwell, transferredsubstrate InP- InGaAs- InP double Heterojunction Bipolar Transistors With $\mathrm{f}_{\mathrm{MAX}}$ of $425 \mathrm{GHz}$, Electronic latters 2001.

[3] Lobisser E, Griffith Z, Jain Z, Thibeault BJ, Rodwell M. 200-nm InGaAs/InP DHBT employing a dual sidewall emitter process demonstracting fmax $>800 \mathrm{GHz}$ and $\mathrm{fT}>360 \mathrm{GHz}$. Presented at IEEE Proc. Indium Phosphide and Related Materials, pp. 16-19, 2009.

[4] Snodgrass W, Freng M. Nano-scale type II InP/InGaAs DHBTs to reach THz cutoff frequencies. Presenté au CS MANTECH Conference, 2008. 